TITLE:

$<$ Note $>$ Evidence of the Leafclipping Behavior by a Chimpanzee of an Unhabituated Group at Mahale

$\operatorname{AUTHOR}(S)$ :

Uehara, Shigeo

CITATION:

Uehara, Shigeo. <Note> Evidence of the Leaf-clipping Behavior by a Chimpanzee of an Unhabituated Group at Mahale. Pan Africa News 2002, 9(1): 3-4

ISSUE DATE:

2002-06

URL:

http://hdl.handle.net/2433/143407

RIGHT:

Copyright (C) Pan Africa News. 


\title{
$<$ NOTE> \\ Evidence of the Leaf-clipping Behavior by a Chimpanzee of an Unhabituated Group at Mahale
}

\author{
Shigeo Uehara \\ Primate Research Institute, Kyoto University
}

After the extinction of the neighboring $\mathrm{K}$ Group to the north in the 1980s (1), no unit group had been confirmed to use extensively the territory of the chimpanzees of M Group, our main study group habituated since the 1970s, except for N Group, which was sometimes seen in the southern periphery of M Group's territory. In the late 1990s, however, some other groups began to invade M Group's territory due probably to the decrease of its group size (2). In the former territory of K Group, unhabituated chimpanzees have recently been observed or heard from time to time as well.

On the 7th March, 2002, accompanied by a Tanzanian research assistant, Hamisi Bunengwa, I tried to see the chimpanzees of the northern unhabituated group. We heard several times chimpanzee pant-hoots and other voice from the area of the upper Mbamba Valley after we reached the ridge between the Mpila and Nkala Valleys from the south at 11:37 (for the study area, see Fig. 1 of ref. (2)). We further proceeded to the north and finally at 13:15 arrived at the ridge between the Mbamba and Kasangazi (shown as Kasangaji in Fig. 1 of ref. 2) valleys where we found quite fresh evidence of the leaf-dipping behavior by a chimpanzee (Figure 1). Although the chimpanzees completely ceased to emit any sound after 12:31 when we were still on the Mpila-Nkala ridge, fresh signs such as their footprints, feces and leftovers of the fruit of Aframomum sp. were seen on several spots after we crossed the Nkala Valley.

The pile of leaves (Psychotria peduncularis (Salisb.) Steyerm.) in Figure 1 must have been made by a chimpanzee of the unhabituated northern group, since (i) most of the chimpanzees of $M$ Group were observed by our colleague to utilize the area to the south of the Ntale Valley (see Fig. 1 of ref. (2)) on the 7th of March, (ii) 


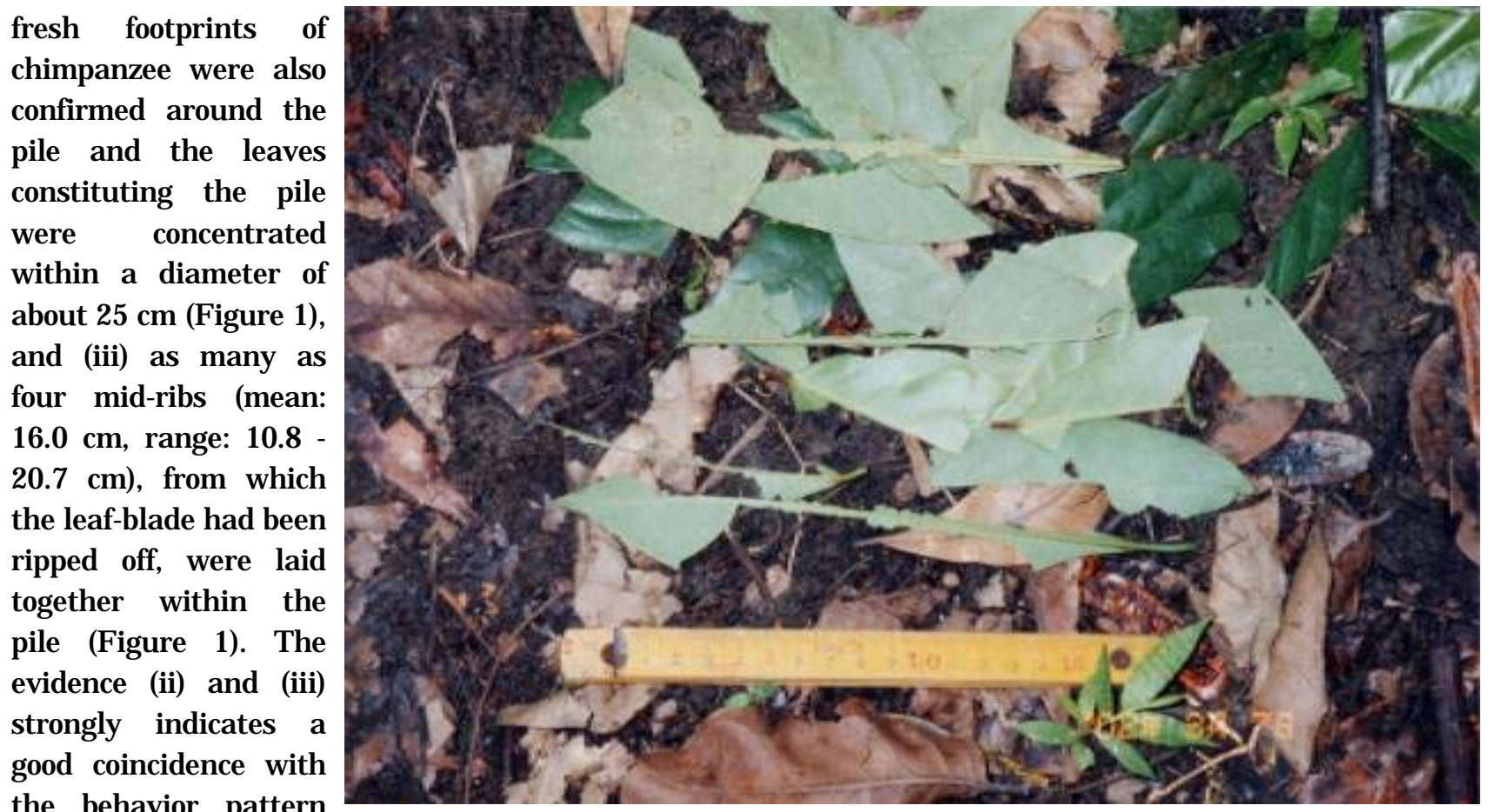

the behavior pattern of the leaf-dipping display by a chimpanzee described

Figure 1. The pile of leaves (Psychotria peduncularis) probably left by a chimpanzee. The four mid-ribs were rearranged laterally for the photographing purpose without altering the circumference of the pile.

by Nishida (3).

The leaf-dipping is regarded as one of the cultural behavior variation among wild chimpanzees; it has never been recorded in some long-term chimpanzee study populations (4). Nishida (3) speculated that the leaf-clipping display may be a signal commonly shared by the local population at Mahale. Tool-use among wild chimpanzees has sometimes been qualified without direct observation of their behavior (e.g., brush-sticks): (5). The present report suggests that indirect evidence may al so be useful in order to prove the existence of the leaf-dipping behavior in unhabituated groups of chimpanzees.

The field work was financed by grant-in-aid for COE Research of the Ministry of Education, Science, Technology, Sports and Culture (Monbu-kagakusho), J apan (\#10CE2005 to O. Takenaka). The Tanzanian authorities (COSTECH, TAWIRI, TANAPA, MMWRC and MMNP) permitted the research. $M$. Shimada and Tanzanian research assistants cooperated in the field. To these people and institutions, I make grateful acknowledgement.

\section{References}

(1) Nishida T, Hiraiwa-Hasegawa M, Hasegawa T, Takahata $Y$ 1985. Group extinction and female transfer in wild chimpanzees of the Mahale Mountains. Z. Tierpsychol. 67: 284-301.

(2) Itoh N, Sakamaki T, Hamisi M, Kitopeni R, Bunengwa $M$, Matumula $M$, Athumani $K$, Mwami M, Bunengwa $\mathrm{H}$ 1999. A new record of invasion by an unknown unit-group into the center of M Group territory. Pan Africa News 6: 8-10.

(3) Nishida T 1980. The leaf-clipping display: A Newly-discovered expressive gesture in wild chimpanzees. J. Hum. Evol. 9: 117-128.

(4) Whiten A, Goodall J , M cGrew WC, Nishida T, Reynolds V, Sugiyama Y, Tutin CEG, Wrangham RW, Boesch C 1999. Cultures in chimpanzees. Nature 399: 682-685.

(5) Sugiyama $Y$ 1985. The brush-stick of chimpanzees found in south-west Cameroon and their cultural characteristics. Primates 26: 361-374. 